\title{
Generation of High Brightness X-rays with the PLEIADES Thomson X-ray Source
}

W.J. Brown, S.G. Anderson, C.P.J. Barty, J.K. Crane, R.R. Cross, D.N. Fittinghoff, F.V. Hartemann, J. Kuba, G.P. Le Sage, D.R. Slaughter, P.T. Springer, A.M. Tremaine, J.B. Rosenzweig, D. Gibson

This article was submitted to the 2003 Particle Accelerator Conference, Portland, OR, May 12-16, 2003

U.S. Department of Energy

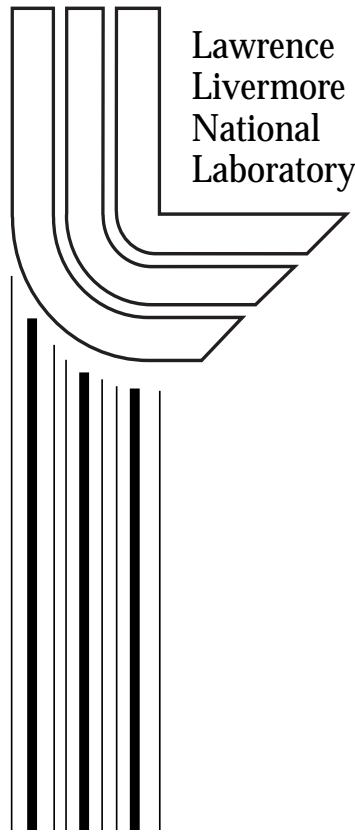

\section{May 28, 2003}




\section{DISCLAIMER}

This document was prepared as an account of work sponsored by an agency of the United States Government. Neither the United States Government nor the University of California nor any of their employees, makes any warranty, express or implied, or assumes any legal liability or responsibility for the accuracy, completeness, or usefulness of any information, apparatus, product, or process disclosed, or represents that its use would not infringe privately owned rights. Reference herein to any specific commercial product, process, or service by trade name, trademark, manufacturer, or otherwise, does not necessarily constitute or imply its endorsement, recommendation, or favoring by the United States Government or the University of California. The views and opinions of authors expressed herein do not necessarily state or reflect those of the United States Government or the University of California, and shall not be used for advertising or product endorsement purposes.

This is a preprint of a paper intended for publication in a journal or proceedings. Since changes may be made before publication, this preprint is made available with the understanding that it will not be cited or reproduced without the permission of the author.

This report has been reproduced directly from the best available copy.

Available electronically at http://www.doc.gov/bridge

Available for a processing fee to U.S. Department of Energy

And its contractors in paper from

U.S. Department of Energy

Office of Scientific and Technical Information

P.O. Box 62

Oak Ridge, TN 37831-0062

Telephone: (865) 576-8401

Facsimile: (865) 576-5728

E-mail: reports@adonis.osti.gov

Available for the sale to the public from

U.S. Department of Commerce

National Technical Information Service

5285 Port Royal Road

Springfield, VA 22161

Telephone: (800) 553-6847

Facsimile: (703) 605-6900

E-mail: orders@ntis.fedworld.gov

Online ordering: http://www.ntis.gov/ordering.htm

\section{OR}

Lawrence Livermore National Laboratory

Technical Information Department's Digital Library

http://www.llnl.gov/tid/Library.html 


\title{
GENERATION OF HIGH BRIGHTNESS X-RAYS WITH THE PLEIADES THOMSON X-RAY SOURCE
}

\author{
W.J. Brown, S.G. Anderson, C.P.J. Barty, J.K. Crane, R.R. Cross, D.N. Fittinghoff, F.V. Hartemann, \\ J. Kuba, G.P. Le Sage, D.R. Slaughter, P.T. Springer, A.M. Tremaine, LLNL, Livermore, CA \\ J.B. Rosenzweig, UCLA, Los Angeles, CA \\ D.J. Gibson, UCD, Department of Applied Science, Livermore, CA
}

\section{Abstract}

The use of short laser pulses to generate high peak intensity, ultra-short x-ray pulses enables exciting new experimental capabilities, such as femtosecond pumpprobe experiments used to temporally resolve material structural dynamics on atomic time scales. PLEIADES (Picosecond Laser Electron InterAction for Dynamic Evaluation of Structures) is a next generation Thomson scattering $\mathrm{x}$-ray source being developed at Lawrence Livermore National Laboratory (LLNL). Ultra-fast picosecond $\mathrm{x}$-rays $(10-200 \mathrm{keV})$ are generated by colliding an energetic electron beam (20-100 MeV) with a high intensity, sub-ps, $800 \mathrm{~nm}$ laser pulse. The peak brightness of the source is expected to exceed $10^{20}$ photons $/ \mathrm{s} / 0.1 \%$ bandwidth $/ \mathrm{mm}^{2} / \mathrm{mrad}^{2}$. Simulations of the electron beam production, transport, and final focus are presented. Electron beam measurements, including emittance and final focus spot size are also presented and compared to simulation results. Measurements of x-ray production are also reported and compared to theoretical calculations.

\section{INTRODUCTION}

PLEIADES (Picosecond Laser Electron InterAction for Dynamic Evaluation of Structures) is a next generation Thomson scattering x-ray source being developed at Lawrence Livermore National Laboratory (LLNL). Ultrafast ps X-rays (10-200 keV) are generated by colliding an energetic electron beam (20-100 MeV) with a high intensity, sub-ps, $800 \mathrm{~nm}$ laser pulse. Generation of subps pulses of hard x-rays $(30 \mathrm{keV})$ has previously been demonstrated at the LBNL Advanced Light Source injector linac, with x-ray beam fluxes of $10^{5}$ photons per pulse [1]. The LLNL source is expected to achieve fluxes between $10^{7}-10^{8}$ photons for pulse durations of $100 \mathrm{fs}$ to 5 ps using interaction geometries ranging from $90^{\circ}$ (sideon collision) to $180^{\circ}$ (head-on collision). In this paper, we describe the first production of $\mathrm{x}$-rays using Thomson scattering at the LLNL facility.

\section{EXPERIMENT LAYOUT}

The PLEIADES facility consists of a Ti-Sapphire laser system capable of producing bandwidth limited laser pulses of $50 \mathrm{fs}$ with up to $500 \mathrm{~mJ}$ of energy at $800 \mathrm{~nm}$, an S-band photo-cathode RF gun, and a $100 \mathrm{MeV}$ linac consisting of 4, 2.5-meter-long accelerator sections. The
$\mathrm{RF}$ gun, which is driven by a picosecond, $300 \mu \mathrm{J}$, UV laser that is synchronized to the interaction drive laser, is designed to produce up to $1 \mathrm{nC}$ of charge at $5 \mathrm{MeV}$ [2]. The accelerator is then used to accelerate the electron beam to energies ranging from 20-100 MeV.

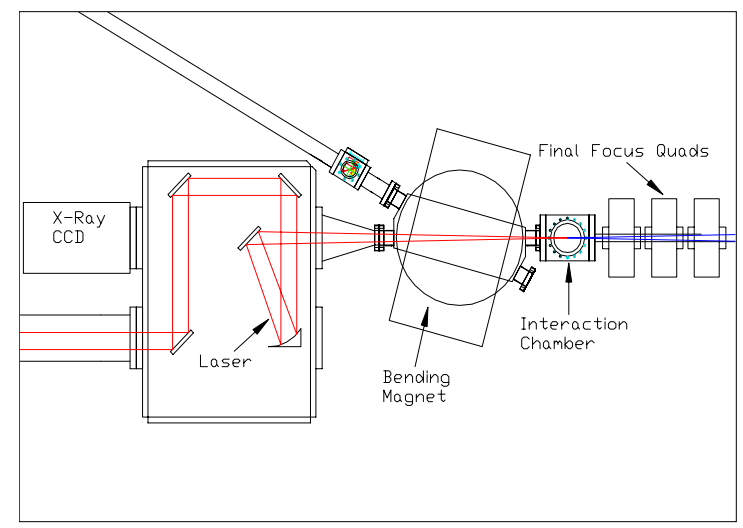

Figure 1: Interaction Geometry

A schematic of the interaction region is shown in Fig. 1. To maximize x-ray flux while minimizing effects of timing jitter, the laser incidence angle is 180 degrees with respect to electron beam direction, though a 90 degree interaction geometry will also be possible in future experiments. The focal length between the final focus quadrupole triplet and the interaction region is $10 \mathrm{~cm}$ to allow for maximum focus strength and minimum electron bunch spot size. A 30-degree dipole magnet is used to bend the electron bunch out of the x-ray beam path following the interaction. An off-axis, $1.5 \mathrm{~m}$ focal length parabolic mirror is used to focus the laser, which, assuming a diffraction limited spot, should reach a minimum spot size of about $15 \mu \mathrm{m}$ FWHM at the interaction point. Currently, a fused-silica flat mirror is placed in the X-ray beam path to serve as the final steering optic for the laser, though there are plans to replace this with a beryllium flat, which will be more transparent to the x-ray beam. The interaction chamber also serves as a diagnostic chamber used for imaging and streak camera analysis of the laser and electron bunches. The x-rays have been measured by a 16 bit CCD array fiber coupled to a cesium iodide scintillator. 


\section{ELECTRON BEAM SIMULATIONS}

The electron beamline has been fully modeled, from the S-band photo-cathode RF gun to the interaction point using the Los Alamos particle dynamics code, PARMELA, and the electrostatic and electromagnetic field solvers: POISSON and SUPERFISH. These include simulations of emittance compensation between the RF gun and the first linac section, velocity compression of the bunch through the first linac section, and the acceleration and optimization of the beam energy spread and emittance during transport through the subsequent accelerator sections.

Two modes of linac operation have been investigated through simulation. The first is when the electron beam is accelerated on crest through the accelerator. In this case, the minimum electron bunch length is about 6 ps FWHM (2.5 ps rms). The second mode of operation employs velocity compression, in which the beam is injected into the first linac section near the zero crossing of the accelerating field in order to provide an energy chirp to the beam. This results in longitudinal compression of the accelerated bunch. The second accelerator section is then used to accelerate the beam from about $10 \mathrm{MeV}$ to about $35 \mathrm{MeV}$. The third and fourth sections can then be used to either remove a large portion of the energy spread induced by the velocity compression process, or to simply accelerate the beam further, depending on the final beam energy desired. Fig. 2 shows the evolution of several of the beam characteristics determined from PARMELA simulations for the case of a $0.5 \mathrm{nC}$ bunch where velocity compression is implemented. At the exit of the accelerator, the electron beam normalized rms emittance is about $3.5 \pi \mathrm{mm}-\mathrm{mrad}$, the rms bunch length is $0.7 \mathrm{ps}$, and the rms energy spread is $0.5 \%$. While it is possible to compress further, this bunch length was chosen to minimize emittance growth resulting from the compression process, while maximizing $\mathrm{x}$-ray yield from the Thomson scattering interaction. In this particular case, the final beam energy is $35 \mathrm{MeV}$, though larger energies are possible with similar results.

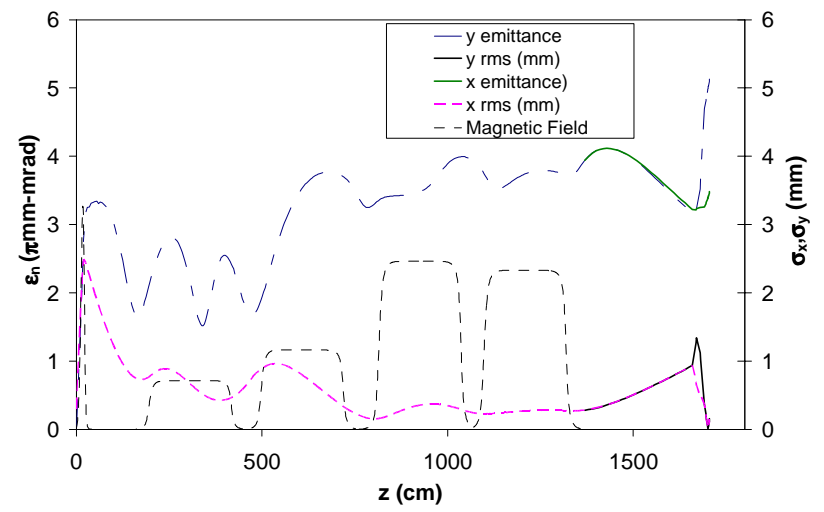

Figure 2: PARMELA simulation of electron beam production from the RF gun to the final focus. Emittance and spot size are plotted vs $z$ position from the RF gun cathode.
The electrons are transported 3 meters from the accelerator exit and focused with a high gradient quadrupole triplet. The triplet is about $50 \mathrm{~cm}$ long, and the focal length is about $10 \mathrm{~cm}$. The maximum field gradient in the quadrupole magnets is $15 \mathrm{~T} / \mathrm{m}$. Final focus simulations were performed using PARMELA and Trace$3 \mathrm{D}$, and have indicated that a spot size of abut $30 \mu \mathrm{m}$ FWHM $(12 \mu \mathrm{m} \mathrm{rms})$ should be obtainable at the focus.

\section{EXPECTED X-RAY PRODUCTION}

The expected $\mathrm{x}$-ray production was calculated by integrating the emission probability per unit time, $d N_{x} / d t$, given by

$$
\frac{d N_{x}}{d t}(t)=\sigma c[1-\mathbf{v} \cdot \mathbf{k}] \iiint n_{y}(\mathbf{x}, t) n_{e}(\mathbf{x}, t) d^{3} x,
$$

where $N_{x}$ is the total number of x-rays produced, $n_{\gamma}(\mathbf{x}, t)$ is the laser photon density, $n_{e}(\mathbf{x}, t)$ is the electron density, $\sigma$ is total Thomson cross section, $\mathbf{v}$ is the velocity of the electron beam, and $\mathbf{k}$ is the wave number of the laser pulse. The calculations were performed for a $300 \mathrm{~mJ}$, 300 fs laser pulse in conjunction with the PARMELA output in place of $n_{e}(\mathbf{x}, t) . n_{\gamma}(\mathbf{x}, t)$ was assumed to have a Gaussian profile in the transverse and longitudinal dimensions, and the Rayleigh range of the laser focus was determined assuming a $2 \mathrm{X}$ diffraction limited focus. For the electron beam parameters determined from the simulation shown in Fig. 2, the peak x-ray energy is 30 $\mathrm{keV}$, and the peak $\mathrm{x}$-ray flux was found to be about $6 \mathrm{x}$ $10^{19}$ photons/s with an integrated photon yield of about $10^{8}$. In addition, a 3-D frequency domain code [3] was used to calculate the expected spectral bandwidth to be about $10 \%$ on axis, with a peak spectral brightness of about $10^{20}$ photons $/ \mathrm{s} / 0.1 \%$ bandwidth $/ \mathrm{mm}^{2} / \mathrm{mrad}^{2}$.

\section{BEAM MEASUREMENTS}

To date, electron bunches with up to $700 \mathrm{pC}$ of charge have been produced with up to $100 \mu \mathrm{J}$ of UV laser energy incident on the gun photo-cathode. The beam has been transported through the linac and accelerated up to 60 $\mathrm{MeV}$ without velocity compression. Quad scan emittance measurements have been performed for $300 \mathrm{pC}, 60 \mathrm{MeV}$ bunches, yielding a normalized rms emittance of $9 \mathrm{~mm}$ mrad. The rms energy spread has been measured to be $0.2 \%$. Improvements in emittance are expected after planned improvements in the UV drive laser uniformity and optimization of the electron beam transport.

Both the electron beam and the interaction drive laser have been imaged by placing a metal cube in the interaction chamber to send OTR light from the electron beam and laser light into the same camera. Using a CCD camera, the electron beam spot sized has been measured to be about $70 \mu \mathrm{m}$ rms, while the laser spot size has been measured to be about $30 \mu \mathrm{m}$. This is about twice the optimized spot size determined from PARMELA simulations, based on the measured beam emittance. 
Further optimization of the final focus quads should help reduce the measured spot size.

The synchronization between the laser and electron bunches has been characterized with a streak camera. A schematic of the measurement, as well as the streak camera image is shown in Fig. 3, indicating good temporal overlap of the two bunches. The jitter has been measured to be within the resolution of the streak camera (about $2 \mathrm{ps}$ ), which is in agreement with indirect timing jitter measurements performed by mixing wakefields produced by the electron bunch with a frequency multiplied photo-diode signal from the laser oscillator.
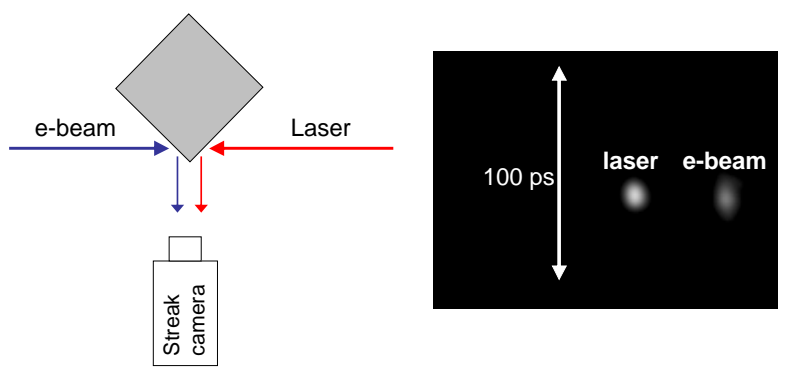

Figure 3: E-beam to laser synchronization measurement.

\section{X-RAY PRODUCTION}

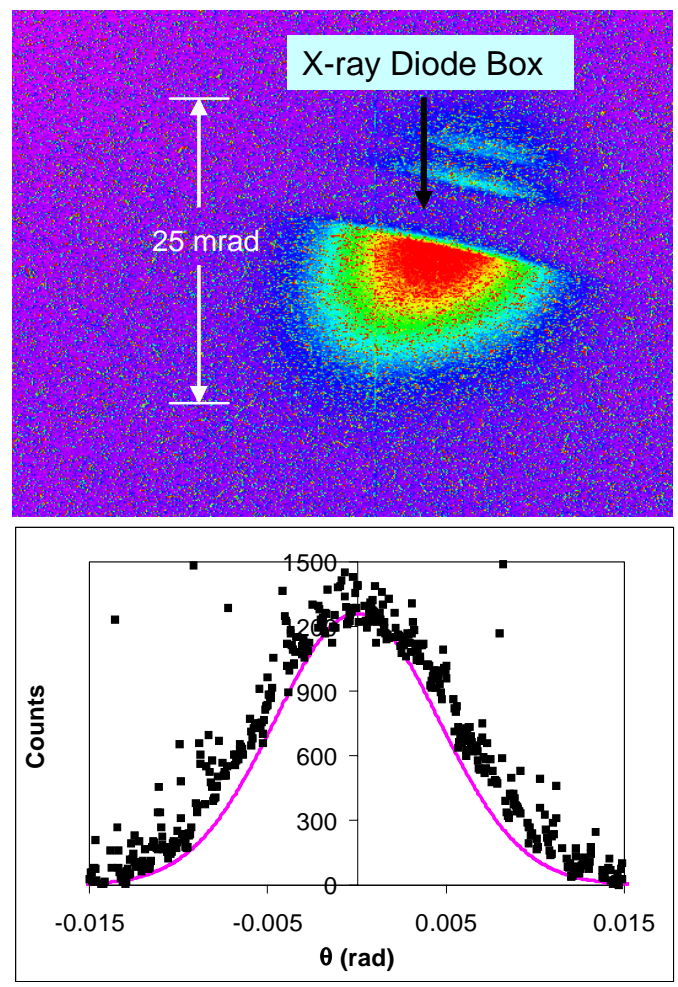

Figure 4: Measurement of X-ray beam profile. Top: CCD image. Bottom: Line-out intensity profile: measurement (dots), theory (line).

First light of the PLEIADES Thomson $\mathrm{x}$-ray source was achieved in January, 2003. Figure 4 shows the measured beam profile taken with the $\mathrm{x}$-ray $\mathrm{CCD}$ camera. The electron beam energy in this case was $54 \mathrm{MeV}$, and the bunch charge was about $250 \mathrm{pC}$. Due to optical misalignments which have since been corrected, the laser energy delivered at the interaction was only about $40 \mathrm{~mJ}$. The image is integrated over 1200 shots. The estimated average photon count per shot is about $5 \times 10^{4}$, and the peak photon energy is about $70 \mathrm{keV}$. The theoretical intensity profile (shown in the bottom half of Fig. 4) agrees well with the measured profile. The theoretical curve includes the broadening effects from the measured beam emittance and the narrowing effects derived from the spectral dependence of the transmission coefficient of the laser turning mirror.

Dramatic improvements of the per shot x-ray dose are expected after improvements in the electron beam final focus optics, maximization of the IR drive laser energy delivered to the interaction region, and reduction of electron beam emittance through the optimization of both the photocathode drive laser uniformity and the electron beam transport. These improvements will allow for the realization of final focus spot sizes as small as $10 \mu \mathrm{m} \mathrm{rms,}$ and the production of up to $10^{8} \mathrm{x}$-ray photons per collision.

\section{CONCLUSIONS}

The PLEIADES Thomson X-ray source is a unique, high peak brightness $\mathrm{x}$-ray source that will be useful for ultra-fast imaging applications to temporally resolve material structural dynamics on atomic time scales. Electron beam transport and x-ray production simulations have been performed to completely model the theoretical source performance. To date, $0.3 \mathrm{nC}, 54 \mathrm{MeV}$ bunches have been focused to $70 \mu \mathrm{m}$ rms spot sized and collided with a $40 \mathrm{~mJ}, 30 \mu \mathrm{m}$ laser pulse to produce $70 \mathrm{keV}$ x-rays. Optimization of the experiment will include increasing the laser energy delivered to the interaction region to about $300 \mathrm{~mJ}$, and decreasing the electron beam emittance to less the $5 \mathrm{~mm}$-mrad rms. This will enable the achievement of a $10 \mu \mathrm{m}$ spot size at the interaction and the production of $10^{8} \mathrm{x}$-ray photons per pulse. Once optimization is complete, PLEIADES should achieve a peak $\mathrm{x}$-ray brightness approaching $10^{20}$ photons $/ \mathrm{s} / 0.1 \%$ bandwidth $/ \mathrm{mm}^{2} / \mathrm{mrad}^{2}$.

\section{ACKNOWLEDGEMENTS}

This work was performed under the auspices of the U.S. Department of Energy by the University of California, Lawrence Livermore National Laboratory under contract No. W-7405-Eng-48.

\section{REFERENCES}

[1] R.W. Schoelein, et. al., Science 274, 236 (1996).

[2] S.G. Anderson, J.B. Rosenzweig, G.P. LeSage, J. Crane, Proceedings of the 2001 Particle Accelerator Conference (Cat. No.01CH37268), p.2260-2 (2001). 
[3] F.V. Hartemann, et. al., Physical Review E, vol.64, (no.1), p.016501/1-26. (2001). 